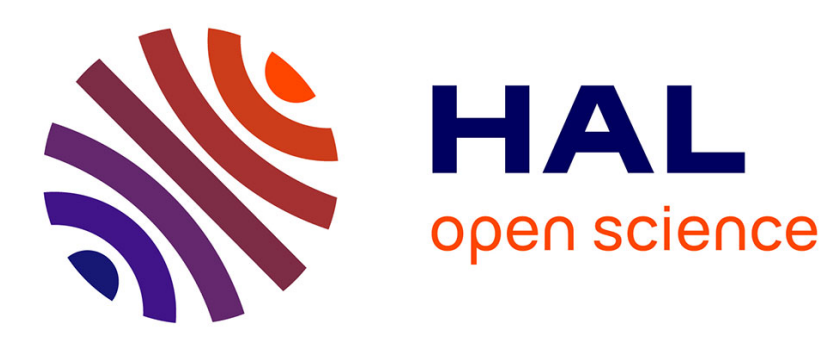

\title{
Piezoelectromechanical structures: a survey of basic concepts and methodologies
}

\author{
Francesco Dell'Isola, E.G. Henneke, Maurizio Porfiri
}

\section{To cite this version:}

Francesco Dell'Isola, E.G. Henneke, Maurizio Porfiri. Piezoelectromechanical structures: a survey of basic concepts and methodologies. Proceedings of Spie - The International Society for Optical Engineering, 2003, pp.10. hal-00495248

\section{HAL Id: hal-00495248 \\ https://hal.science/hal-00495248}

Submitted on 25 Jun 2010

HAL is a multi-disciplinary open access archive for the deposit and dissemination of scientific research documents, whether they are published or not. The documents may come from teaching and research institutions in France or abroad, or from public or private research centers.
L'archive ouverte pluridisciplinaire HAL, est destinée au dépôt et à la diffusion de documents scientifiques de niveau recherche, publiés ou non, émanant des établissements d'enseignement et de recherche français ou étrangers, des laboratoires publics ou privés. 


\title{
Piezoelectromechanical structures: a survey of basic concepts and methodologies
}

\author{
F. dell'Isola*a ${ }^{* a}$ E.G. Henneke ${ }^{\mathrm{b}}$, M. Porfiri ${ }^{\mathrm{c}}$ \\ "Dip. di Ingegneria Strutturalè e Geotecnica, Università di Roma "La Sapienza", Roma, Italia; \\ 'Dept. Engineering Sciences and Mechanics, "Virginia Tech", Blacksburg, VA, USA; \\ "Dottorato in Meccanica Teorica e Applicata, Università di Roma "La.Sapienza", Roma, Italia
}

$1-6-2003$

\begin{abstract}
In the litcrature distributed arrays of piezeoclectric patches are employed to activcly control structural vibrations. In the present work in order to damp beam vibrations a completely passive electric controller is proposed, exploiting distributed piczoelectric transduction. The optimization of the distributed clectric controller is performed analyzing the free wave propagation in the composite smart beam. The proposed controller allows for an optimal attenuation of wave propagation over any frequency range. A prototype of the proposed novel smart structure (Piczo-ElectroMechanical beam) is designed, allowing for appreciating its technical feasibility and effectiveness.
\end{abstract}

Keywords: Sinart structures, wave propagation, piezoclectric transducers, distributed control, coupled problems.

\section{Introduction}

The aim of this paper is to prove that attenuation of wave propagation over any frequency band is technically fcasible, when cxploiting purcly passive alectric networks and available piezoelectric transducers. Indecd the authors prove that multimodal dampirg of mechanical vibrations by means of truly passive electric circuits can be obtaincd by uniformly distributing piczoclectric transduccrs on the host structure and suitably designing an optimal interconnecting clectric passive network (the resulting smart structure is called PiezoElectroMechanical structure, $\mathbb{P E M}$ for brevity). This concept scems an interesting development of the method of "piczoclectric shimuting" proposed by Hagood and von Flotow in ${ }^{1}$ for single mode and extended by Hollkamp and Fleming, Behrens and Moheimani to multimodal control $\left({ }^{2}\right.$ and $\left.^{3}\right)$. Indecd the method here presented is based on the shunting of an array of distributed piezoelcctric transducers with multiterminal terminals passive electric network: more preciscly, instcad of coupling each piczoelectric transducer to a single (eventually multifrequency) elcctric resonator, the whole set of transducers is coupled to a distributed electric network. It has to be remarked that the electric controller which is introduced evolves with differential equations coupled to those governing the evolution of the mechanical system to be controlled and therefore the concept introduced here differs from that studied

\footnotetext{
* francesco.dell'isola (Ouniromal.it; phone (+39)0644585297.
} 
in, ${ }^{4}{ }^{5}$ Indecd, in the quoted papers the distributed array of piezoelectric transducers is actively driven by a voltage ficld, which is the output of a suitable feed-back loop (in this way one gets a smart structure which is in general non-conservative). Instcad, the piezoelectric controller here introduced is a completely passive controller, so that $\mathbb{P E M}$ structures are passive.

In Scction 2 a refined (microscopic) model for $\mathbb{P E M}$ beams is introduced, in which the lumped nature of the electric network and the localization of piezoclectric applied couples are accounted for.

In Section 3 the homogenized model is deduced from the previously introduced refined model. Such a homogenized model:

1. is valid when the wave length is sufficiently larger than the size of each piezoelectric clement,

2. is more handlcable when seeking passive optimal controllers,

3. is sufficiently detailed to suggest design criteria for truly lumped $\mathbb{P E M}$ beams.

In Section 4 the electromechanical wave propagation in homogenized $\mathbb{P E M}$ beams is addressed, without specifying completely the evolution equations of the electric controller, which is assumed to belong to a rather wide class of (local) differential controllers.

In Section 5 the pole placement technique is exploited to determine - in the class previously specified - the optimal passive electric controller.

In Scction 6 the theoretical results previously established are exploited to start the design of a prototypc $\mathbb{P E M}$ beam.

\section{Refined model for $\mathbb{P E M}$ beams}

We consider an unlimited host beam of width $w$ and thickness $h$ on which an array of uniformly distributed piczoclectric transduccers is positioned as shown in Fig. 1 (covering both the beam faces). The length of the transducers is assumed to be cqual to $l_{p}$, while the width is assumed to be equal to that of the beam; $d$ denotes the distance between the adjacent patches.

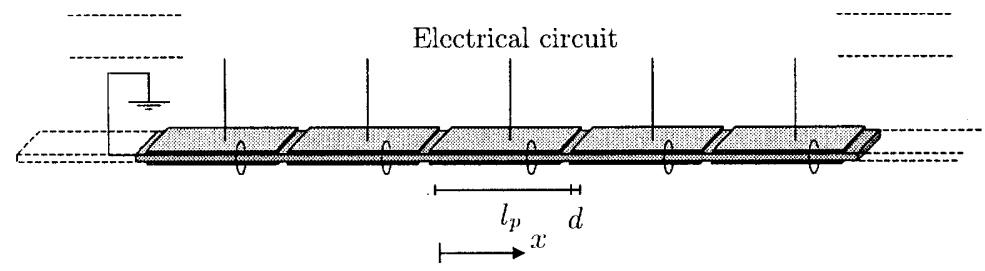

Figure 1: Geometry of the problem.

The piczotransduccrs are placed along the beam axis and polarized in the transverse dircetion, in the so called bender configuration (sce c.g. ${ }^{6}$ ). These transducers will be interconnected by an clectrical network which will be synthesized in order to accomplish given optimality conditions on the attenuation of propagating waves. 
Introducing a set of nodes $\left\{x_{i}\right\}$ representing the geometrical centers of the transducers, defined by:

$$
x_{i}=\left(l_{p}+d\right) i
$$

the contact couple $M$ at the section labelled by the abscissa $x$, over the beam span, can be cxpressed as the sum of mechanical and piczoelectric contributions as follows ${ }^{6}$ :

$$
M(x, t)=\left[E_{b} I_{b}+k_{m m} \sum_{i=-\infty}^{+\infty}\left(\operatorname{RECT}_{l_{p}}\left(x-x_{i}\right)\right)\right] u^{\prime \prime}(x, t)+k_{m e} \sum_{i=-\infty}^{+\infty}\left(\operatorname{RECT}_{l_{p}}\left(x-x_{i}\right) \dot{\psi}_{i}(t)\right),
$$

where:

$$
\left\{\begin{array}{rl}
\operatorname{RECT}_{l_{p}}\left(x-x_{i}\right) & =\mathrm{H}\left(x-x_{i}-\frac{l_{p}}{2}\right)-\mathrm{H}\left(x-x_{i}+\frac{l_{p}}{2}\right) \\
k_{m m} & =\frac{h^{2} w \delta}{2 s_{11}^{E}} ; \quad k_{m e}=\frac{h w d_{31}}{s_{11}^{E}}
\end{array} ;\right.
$$

$\mathrm{H}$ is the Heaviside function, $\psi_{i}$ is the flux linkage ${ }^{1}$ of the $i$-th transducer measured with respect to a common reference ground for every transducer, $u$ is the beam deflection field, $E_{b}$ is the Young modulus of the material of the beam, $I_{b}$ is the beam section moment of inertia $\left(I_{b}=h^{3} w / 12\right), \delta$ is the transducers thickness, $s_{11}^{E}$ is the piczoclectric mechanical compliance, $d_{31}$ is the piezoelectric coupling coefficient, $t$ denotes the time variable and superposed dot and prime respectively mean time and space derivative. The distributed incrtia can be accounted for by introducing the following constitutive equation for the applied load (external mechanical forcing is excluded):

$$
b_{T}(x, t)=-w h\left(\rho_{b}+2 \frac{\delta}{h} \sum_{i=-\infty}^{+\infty}\left(\operatorname{RECT}_{l_{p}}\left(x-x_{i}\right)\right) \rho_{p}\right) \ddot{u}(x, t)
$$

where $\rho_{l}$, and $\rho_{p}$ are respectively the mass density per unit volume of the beam and transducer matcrials.

The balance equations for the considered electrically excited vibrating beam yield:

$$
M(x, t)^{\prime \prime}-b_{T}(x, t)=0
$$

when $M(x, t)$ and $b_{T}(x, t)$ are given by Eqns. (2) and (4) respectively.

From a purcly clectrical point of view the $i$-th piezoelectric bender transducer can be described as a capacitor in parallel connection with a "mechanically driven" current source, which injects into the electrical circuit the current, $J_{i}$ driven by its mechanical time rate of deformation (see Fig. 2)

$$
J_{i}=k_{m e}\left(\dot{u}^{\prime}\left(x_{i}+l_{p} / 2, t\right)-\dot{u}^{\prime}\left(x_{i}-l_{p} / 2, t\right)\right) .
$$

The capacitance of cach piezoelectric bender transducer can be estimated to be cqual to ${ }^{6}$ :

$$
k_{e e}=2 \frac{w\left(s_{11}^{E} \epsilon_{3}^{T}-d_{31}^{2}\right)}{s_{11}^{E} \delta} l_{p}
$$

The electrical system interconnecting the electrical terminals of the bender transducers is assumed to be a multiterminal network the admittance $Y_{i j}^{e}$ of which, in the Laplace domain, is given by:

$$
Y_{i j}^{e}=D_{i j}^{e}+\frac{1}{s} K_{i j}^{e}
$$

\footnotetext{
${ }^{1}$ The flux linkage $\psi_{i}$ represents the time integral of the voltage $V_{i}$ of the $i$-th transducer measured with respect to the common ground, i.e. $\dot{\psi}_{i} \equiv V_{i}$.
} 


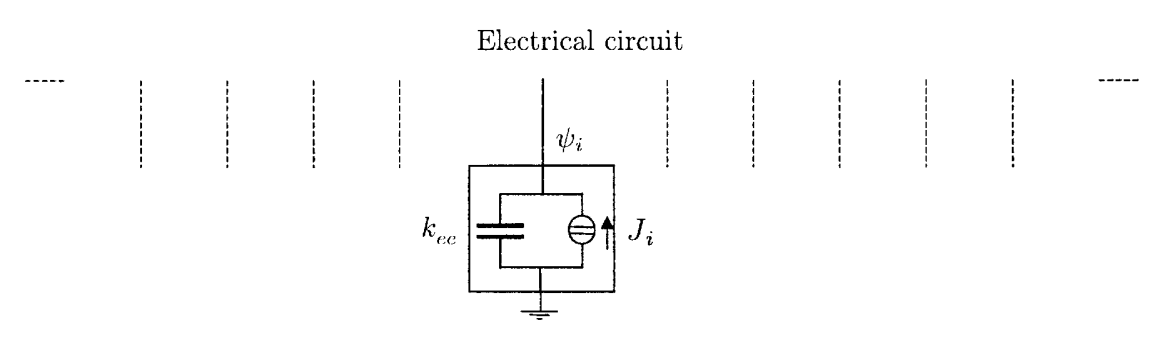

Figure 2: Sketch of the mechanically fed electric controller.

where $s$ is the Laplace transform variable and the residues $K_{i j}^{e}$ (electrical stiffness) and $D_{i j}^{e}$ (clectrical damping) are assumed to have finite bandwidth $2 N-1$.

Thus, by Kirchhoff balance of currents at node $i$, the evolution equations for the variables $\psi_{j}$ are given by the following sccond order system of ODEs:

$$
k_{e e} \ddot{\psi}_{i}+\sum_{j=i-N}^{i+N} K_{i j}^{e} \psi_{j}+\sum_{j=i-N}^{i+N} D_{i j}^{e} \dot{\psi}_{j}-k_{m e}\left(\dot{u}^{\prime}\left(x_{i}+l_{p} / 2, t\right)-\dot{u}^{\prime}\left(x_{i}-l_{p} / 2, t\right)\right)=0
$$

\section{A class of Homogenized models for $\mathbb{P E M}$ beams}

When it can be assumed that the number of piezoelectric transduccrs is sufficiently large, a continuous flux linkage ficld $\psi(x, t)$ can be introduced and the bending moment constitutive relation (2) becomes (for more details on the needed homogenization techniques $\left.\sec ^{4}\right)$ :

$$
M=\left(E_{b} I_{b}+c_{f} k_{m m}\right) u^{\prime \prime}+c_{f} k_{m e} \dot{\psi}
$$

where $c_{f}$ represents a covering factor defined as:

$$
c_{f}=\frac{1}{1+d / l_{p}}
$$

while the applied load (4) becomes:

$$
b_{T}=-w h\left(\rho_{b}+2 c_{f} \frac{\delta}{h} \rho_{p}\right) \ddot{u}
$$

The governing equation cxpressed in terms of the deflection $u$ is readily scen to be:

$$
K_{M} u^{I V}+\rho \ddot{u}+c_{f} k_{m e} \dot{\psi}^{\prime \prime}=0,
$$

with:

$$
\left\{\begin{array}{c}
K_{M}=E_{b} I_{b}+c_{f} k_{m m} \\
\rho=w h\left(\rho_{b}+2 c_{f} \frac{\delta}{h} \rho_{p}\right)
\end{array}\right.
$$


Thus the dimcnsionless form of the mechanical evolution cquation becomes:

$$
\ddot{u}+\alpha^{4} u^{I V}+\beta_{e m}^{2} \dot{\psi}^{\prime \prime}=0, \quad\left\{\begin{array}{c}
\alpha^{4}=\frac{K_{M}}{l^{4} \rho \omega_{0}^{2}} \\
\beta_{e m}^{2}=\frac{c_{f} k_{m e} \psi_{0}}{l^{2} \rho \omega_{0} u_{0}}
\end{array},\right.
$$

where a characteristic frequency $\omega_{0}$, a characteristic length equal to the beam length $l$, a characteristic deflection $u_{0}$ and a characteristic flux linkage $\psi_{0}$ have becn introduced. As this cannot causc misunderstanding, we have adopted the same letters to denote both dimensional and dimensionless differential operators and kinematical descriptors.

Furthermore, when the number of transducers can be assumed to be sufficiently large, the electrical system can be described by a solc PDE which, expressed in terms of the dimensionless flux-linkage $\psi$, reads:

$$
\ddot{\psi}+\mathbf{K}[\psi]+\mathbf{D}[\dot{\psi}]-\beta_{m e}^{2} \dot{u}^{\prime \prime}=0, \quad \beta_{m e}^{2}=\frac{k_{m e} u_{0}}{l^{2}\left(\frac{k_{e e}}{l_{p}}\right) \omega_{0} \psi_{0}}
$$

where it is assumed that $\mathbf{K}$ and $\mathbf{D}$ are (local) spatial differential operators of the following form:

$$
\left\{\begin{array}{l}
\mathbf{K}[\psi]=\sum_{i=0}^{A}(-1)^{i} a_{2 i} \frac{d^{(2 i)} \psi}{d x^{(2 i)}} \\
\mathbf{D}[\dot{\psi}]=\sum_{i=0}^{B}(-1)^{i} b_{2 i} \frac{d^{(2 i)} \dot{\psi}}{d x^{(2 i)}}
\end{array},\right.
$$

and $a_{2 i}$ and $b_{2 i}$ are positive real constants to assure the passivity of the interconnecting network, and the indices $A$ and $B$ arc positive.

This hypothesis on the structure of the electrical stiffness and damping, respectively $\mathbf{K}[\cdot]$ and $\mathbf{D}[\cdot]$, scems to be general cnough for our design aims and leads to a simple solution of the synthesis problem of determining an optimal lumped clectrical circuit to be piczoelectrically coupled to the given flexible structure.

Thus the dimcnsionless form of the cvolution electromechanical equations is:

$$
\left\{\begin{array}{c}
\ddot{u}+\alpha^{4} u^{I V}+\beta^{2} \dot{\psi}^{\prime \prime}=0 \\
\ddot{\psi}+\mathbf{K}[\psi]+\mathbf{D}[\dot{\psi}]-\beta^{2} \dot{u}^{\prime \prime}=0
\end{array} ; \quad\left\{\begin{array}{c}
\alpha^{4}=\frac{K_{M}}{l^{4} \omega_{0}^{2} \rho} \\
\beta^{2}=\frac{k_{m e}}{l^{2} \omega_{0}} \sqrt{\frac{c_{f} l_{p}}{k_{e e} \rho}}
\end{array}\right.\right.
$$

where, in order to preserve the form of a gyroscopic coupling, the characteristic flux linkage and displacement are chosen to satisfy the following relation:

$$
\sqrt{\frac{c_{f} k_{e e}}{l_{p} \rho}}=\frac{u_{0}}{\psi_{0}}
$$

Let us underline that the quantity

$$
\frac{c_{f} k_{e e}}{l_{p}}=: \gamma
$$

represents the capacitance per unit length of the $\mathbb{P} \mathbb{E M}$ beam.

The coupling coefficient $\beta^{2}$ can be cxpressed in the following form:

$$
\beta^{2}=\left(c_{f} k_{m e}\right) \frac{1}{l^{2} \omega_{0}} \sqrt{\frac{1}{\gamma \rho}}
$$

The class of differcntial opcrators of the form (11) has been considered for the following rcasons: 
1. when boundary conditions are introduced, the electrical system piezoelectrically coupled to the flexible structure does not introduce any spillover phenomenon among the mechanical vibration modes;

2. the synthesis of an clectrical circuit governed by a discrete form of these operators is very casy, exploiting the methods adopted in ${ }^{6}$;

3. it includes at least two interesting interconnection schemes for piezoclectric arrays, developed in the vibration control litcrature $\left(,,^{18}\right)$.

When the stiffness opcrator is limited at the 0 term every piczoelectric element is interconnected to a single grounded inductor and no "cooperation" cxists in between the piezoelectric transducers. When only the second term is accounted for, cach piczoclectric transducer is connected to the adjacent one by a floating inductor, providing a second order transmission line piezoelectrically coupled to the vibrating structure $\left({ }^{8}\right)$.

\section{Wave propagation in homogenized $\mathbb{P E M}$ beams}

In this subsection the wave propagation analysis in a $\mathbb{P E M}$ bcam is performed.

Let us consider the wave solution of (12):

$$
\left[\begin{array}{l}
u(x, t) \\
\psi(x, t)
\end{array}\right]=\left[\begin{array}{l}
U \\
\Psi
\end{array}\right] e^{\left(-i \frac{2 \pi}{\lambda} x+s t\right)}
$$

in tcrms of the wave length $\lambda \in \mathbb{R}^{+}$and the Laplace transform variable $s \in$ C. Substituting (14) into (12), with simple algebraic manipulations we obtain

$$
\left\{\begin{array}{c}
s^{2} U+\alpha^{4}\left(\frac{2 \pi}{\lambda}\right)^{4} U-\beta^{2} s\left(\frac{2 \pi}{\lambda}\right)^{2} \Psi=0 \\
s^{2} \Psi+P_{\mathbf{K}}\left[\frac{2 \pi}{\lambda}\right] \Psi+s P_{\mathbf{D}}\left[\frac{2 \pi}{\lambda}\right] \Psi+\beta^{2} s\left(\frac{2 \pi}{\lambda}\right)^{2} U=0
\end{array}\right.
$$

where the polynomials $P_{\mathrm{K}}\left[\frac{2 \pi}{\lambda}\right]$ and $P_{\mathrm{D}}\left[\frac{2 \pi}{\lambda}\right]$ are defined by the following

$$
\left\{\begin{array}{l}
P_{\mathbf{K}}\left[\frac{2 \pi}{\lambda}\right]=\sum_{i=0}^{A} a_{2 i}\left(\frac{2 \pi}{\lambda}\right)^{2 i} \\
P_{\mathbf{D}}\left[\frac{2 \pi}{\lambda}\right]=\sum_{i=0}^{B} b_{2 i}\left(\frac{2 \pi}{\lambda}\right)^{2 i}
\end{array} .\right.
$$

The algebraic equations (15) yicld the following dispersion relation:

$$
s^{4}+P_{\mathbf{D}}\left[\frac{2 \pi}{\lambda}\right] s^{3}+\left(\left(\alpha \frac{2 \pi}{\lambda}\right)^{4}+\left(\beta \frac{2 \pi}{\lambda}\right)^{4}+P_{\mathbf{K}}\left[\frac{2 \pi}{\lambda}\right]\right) s^{2}+P_{\mathbf{D}}\left[\frac{2 \pi}{\lambda}\right]\left(\alpha \frac{2 \pi}{\lambda}\right)^{4} s+\left(\alpha \frac{2 \pi}{\lambda}\right)^{4} P_{\mathbf{K}}\left[\frac{2 \pi}{\lambda}\right]=0
$$

\section{Design of the passive optimal controller}

In this section we will design the optimal passive distributed controller following the pole placement technique applied to the evolution of each pair of electrical and mechanical waves. In particular, we will determine an optimal expression for the stiffness and dissipative polynomials $P_{\mathbf{K}}$ and $P_{\mathbf{D}}$ appearing in (15); consequently, we will establish the forms of the opcrators $\mathbf{K}$ and $\mathbf{D}$. 
The chosen optimality condition requires the determination of the values of $P_{\mathbf{K}}$ and $P_{\mathrm{D}}$ in order to maximize the exponential time decay rate $\tau^{\lambda}$ of the electromechanical wave propagating with the wavelength $\lambda$, defined as:

$$
\tau^{\lambda}=\min _{i=1, \ldots 4}\left\{\left|\operatorname{Re}\left[s_{i}^{\lambda}\right]\right|\right\}
$$

$s_{i}^{\lambda}$ boing the zcros of $(17)$.

In order to maximize the exponential time decay $\tau^{\lambda}$, the optimal cxpressions of $P_{\mathbf{K}}$ and $P_{\mathbf{D}}$ are found by requiring the four zeros $s_{i}^{\lambda}$ to be coincident (pole placement technique, sce e.g. ${ }^{1}$ and $^{9}$ ).

Hence we cnforce the polynomial in the RHS of (17) to be factorized as:

$$
\left(s^{2}+2 \sigma[\lambda] s+\left(\sigma[\lambda]^{2}+\omega[\lambda]^{2}\right)\right)^{2} .
$$

Equating the coefficients of the above mentioned polynomials the following set of conditions is obtained:

$$
\left\{\begin{array}{l}
P_{\mathrm{D}}\left[\frac{2 \pi}{\lambda}\right]=4 \sigma[\lambda] \\
\left(\left(\alpha \frac{2 \pi}{\lambda}\right)^{4}+\left(\beta \frac{2 \pi}{\lambda}\right)^{4}+P_{\mathbf{K}}\left[\frac{2 \pi}{\lambda}\right]\right)=6 \sigma[\lambda]^{2}+2 \omega[\lambda]^{2} \\
P_{\mathrm{D}}\left[\frac{2 \pi}{\lambda}\right]\left(\alpha \frac{2 \pi}{\lambda}\right)^{4}=4 \sigma[\lambda]^{3}+4 \sigma[\lambda] \omega[\lambda]^{2} \\
\left(\alpha \frac{2 \pi}{\lambda}\right)^{4} P_{\mathrm{K}}\left[\frac{2 \pi}{\lambda}\right]=\left(\sigma[\lambda]^{2}+\omega[\lambda]^{2}\right)
\end{array}\right.
$$

The previous set of relations imposes the following matching conditions on the electrical controller:

$$
\left\{\begin{array}{l}
P_{\mathbf{K}}\left[\frac{2 \pi}{\lambda}\right]=\left(\alpha \frac{2 \pi}{\lambda}\right)^{4} \\
P_{\mathbf{D}}\left[\frac{2 \pi}{\lambda}\right]=2\left(\beta \frac{2 \pi}{\lambda}\right)^{2}
\end{array} .\right.
$$

Consequently, from Eqns. (18) the values of the real and imaginary part of the coincident roots are found to be:

$$
\left\{\begin{array}{l}
\sigma[\lambda]=\frac{\left(\beta \frac{2 \pi}{\lambda}\right)^{2}}{2} \\
\omega[\lambda]=\sqrt{\left(\alpha \frac{2 \pi}{\lambda}\right)^{4}-\frac{\left(\beta \frac{2 \pi}{\lambda}\right)^{4}}{4}}
\end{array}\right.
$$

hence, the damping ratio (defined as the sine of the phase of the coincident roots measured from the imaginary axis) becomes:

$$
\varsigma[\lambda]:=\frac{\sigma[\lambda]}{\sqrt{\omega[\lambda]^{2}+\sigma[\lambda]^{2}}}=\frac{\beta^{2}}{2 \alpha^{2}} .
$$

Taking into account the definitions (12) of the parameters $\alpha$ and $\beta$, we get the following expression in terms of the propertics of the piezo-electromechanical beam:

$$
\varsigma[\lambda]=\frac{c_{f} k_{m e}}{2 \sqrt{\gamma K_{M}}}
$$

Finally, let us express the damping ratio as a function of the piezoclectric matcrial charactcristics, the beam goometry and matcrial propertics by:

$$
\varsigma[\lambda]=\frac{\sqrt{c_{f}} \sqrt{\frac{\delta}{h}}}{\sqrt{\frac{2}{3}\left(E_{b} s_{11}^{E}\right)+4 c_{f} \frac{\delta}{h}} \sqrt{\left(\frac{1}{k_{31}^{2}}-1\right)}}, \quad k_{31}=d_{31} \sqrt{\frac{1}{s_{11}^{E} \epsilon_{3}^{T}}} ;
$$


whore the clectromechanical coupling coefficient $k_{31}$ has been introduccd.

Equation (22) clcarly indicates that the damping ratio is independent of the mode under control and is an increasing function of the variables:

1. electromechanical coupling coefficient $k_{31}$;

2. ratio of the patches thickness over the beam thickness $\frac{\delta}{h}$;

3. covering factor $c_{f}$;

4. ratio of the patches clastic modulus over the beam Young modulus $\left(E_{b} s_{11}^{E}\right)^{-1}$.

Conditions (16) establish that the optimal distributed passive circuit to be mechanically fed by the piezotransduccrs has to be governed by the following PDE:

$$
\ddot{\psi}+\mathbf{K}[\psi]+\mathbf{D}[\dot{\psi}]=0
$$

where the stiffness and damping operators are defined by:

$$
\left\{\begin{array}{l}
\mathrm{K}[\psi]=\alpha^{4} \psi^{I V} \\
\mathrm{D}[\dot{\psi}]=-2 \beta^{2} \dot{\psi}^{\prime \prime}
\end{array},\right.
$$

REMARK 1. The found electrical interconnecting network can be thought as the beam analog circuit, with an internal dissipation proportional to the curvature velocity $\dot{u}^{\prime \prime}$. This circuit guarantees the maximum exponential time rate decay $\tau^{\lambda}$ for every wavelength $\lambda$. Exploiting different circuits included in (11) it is possible to maximize $\tau^{\lambda}$ only at a given wavelength $\bar{\lambda}$.

The synthesis problem of finding an analog circuit of the Euler beam has been addressed in ${ }^{10}$ and. ${ }^{6}$

\section{Design of a prototype}

In order to assess the physical realizability and the efficiency of the proposed device, we will consider an aluminum bcam, the geometry of which is presented in table 1:

Table 1: Properties and dimensions of the host beam.

\begin{tabular}{|c|c|c|} 
Coefficient & Value & Units \\
\hline \hline$w$ & 2 & $\mathrm{~cm}$ \\
\hline$h$ & 2 & $\mathrm{~mm}$ \\
\hline$E$ & 70 & $\mathrm{GPa}$ \\
\hline$\rho_{b}$ & 2700 & $\mathrm{~kg} / \mathrm{m}^{3}$ \\
\hline
\end{tabular}

Let us exploit bender transducers constituted by piezocoramic patches made of lead zirconate titanate [PZT] (for more details on the different kinds of piezoclectric actuations see ${ }^{11}$ ).

The characteristics of these piezoceramic transducers are listed in table 2 . 
Table 2: Propertics and dimensions of the the piezoelectric transducers (Piezo System T110-H4E-602, made of PSI-5H4 piccoccramic).

\begin{tabular}{|l|l|l|}
\hline Coefficient & Value & Units \\
\hline \hline$\rho_{p}$ & 7800 & $\mathrm{~kg} / \mathrm{m}^{3}$ \\
\hline$\left(s_{11}^{E}\right)^{-1}$ & 62 & $G P a$ \\
\hline$d_{31}$ & $32010^{-12}$ & $\mathrm{~m} / \mathrm{V}$ \\
\hline$\epsilon_{3}^{T}$ & $38008.8510^{-12}$ & $\mathrm{~F} / \mathrm{m}$ \\
\hline$\delta$ & .267 & $\mathrm{~mm}$ \\
\hline$l_{p}$ & 25 & $\mathrm{~mm}$ \\
\hline$d$ & 2.273 & $\mathrm{~mm}$ \\
\hline
\end{tabular}

'Thus the covering factor can be estimated to be:

$$
c_{f}=91.67 \%
$$

While the capacitance and coupling cocfficient of the bender transducers are:

$$
\left\{\begin{array}{c}
k_{e e}=2 \frac{w\left(s_{11}^{E} \epsilon_{3}^{T}-d_{31}^{2}\right)}{s_{11}^{E} \delta} l_{p}=184.9 n F \\
k_{m e}=\frac{h w d_{31}}{s_{11}^{E}}=1.43610^{-3} \mathrm{C}
\end{array} .\right.
$$

The stiffness and mass per unit length of the PEM beam can be evaluated to be:

$$
\left\{\begin{array}{c}
K_{M}=E_{b} I_{b}+c_{f} k_{m m}=2.032 \mathrm{Nm}^{2} \\
\rho=w h\left(\rho_{b}+2 c_{f} \frac{\delta}{h} \rho_{p}\right)=0.2462 \mathrm{Kg} / \mathrm{m}
\end{array} .\right.
$$

From Eqn. (21) the damping ratio of any propagating wave is determined to be:

$$
\varsigma[\lambda]=17.74 \%
$$

\section{Conclusions}

In the present paper the concept of piczoelectric shunting by means of a single transduccr suitably positioned on a structural member is generalized. Indeed we consider a beam hosting an array of uniformly distributed piczoclectric transduccrs and look for a distributed electric network shunting them in an optimal way. If waves with wavelength reasonably greater than the size of the used transducers are considered, then we expect that the homogenized model for the controller may be suitable. In Section 3 such an infinite dimensional model is found, while in the subsequent sections its clectric components are optimized to get the most efficient damping of electromechanical waves. We have proved that, in principles, a wavelength independent (i.c. a complete broadband) wave attenuation is possible by means of a completely passive electric controller. This is obtained by synthesizing a distributed clectric circuit governed by the same PDE governing the beam flexural vibrations. However, the synthesis is achieved by the use of lumped circuital components, therefore the following problem arises: how efficient the finite dimensional circuit results are when compared with their homogenized counterpart. This is a crucial issuc when prototypes of $\mathbb{P E M}$ beams must be designed, as sketched in the final section. 
Future works will be devoted to the comparison between the performances of homogenized electric controllers and their lumped approximations.

Acknowledgment: The partial support of the Engineering Science and Mechanics Department of Virginia Polytechnic Institute and Statc University is gratefully acknowledged by the authors. This presented research has been also partially supported by MIUR, Ministero per l'Innovazione, l'Università e la Ricerca Fondi Ricerca PRIN "Sintesi di circuiti piezoclettrici e tecniche di disaccoppiamento per il controllo di vibrazioni meccaniche" (protocollo 2001097882_003) and by the Università di Roma "La Sapienza".

\section{REFERENCES}

[1] N. W. Hagood and A. von Flotow, "Damping of structural vibrations with piczoclectric matcrials and passive elcctrical networks", Journal of Sound and Vibrations 146, 243-268, 1991.

[2] J. J. Hollkamp, "Multimodal Passive Vibration Suppression with Piezoelectric Matcrials and Rcsonant Shunts", Journal of Intelligent Material Systems and Structures 5, 49-57, 1994.

[3] A. J. Flcming, S. Behrens, and S. O. R. Moheimani, "Optimization and Implementation of Multimode Piezoclectric Shunt Damping Systems", IEEE/ASME Transactions on Mechatronics 7(1), 87-94, 2002.

[4] M. Kader, M. Lenczner, and Z. Mrcarica, "Distributed control based on distributed clectronic circuits: application to vibration control", Microelectronics Reliability 41, 1857-1866, 2001.

[5] D. Halim, and S. O. R. Mohcimani, "Expcrimental Implementation of Spatial $\mathcal{H}_{\infty}$ Control on a PiezoclectricLaminate Bcam", IEEE/ASME Transactions on Mechatronics 7(3), 346-356, 2002.

[6] U. Andrcaus, F. dell'Isola, and M. Porfiri, "Piczoclectric passive distributed controllcrs for bcam flexural vibrations", to appear in Journal of Vibration and Control.

[7] R. W. Newcomb, Linear Multiport Synthesis, McGraw Hill, New York, 1966.

[8] S. Vidoli, F. dell'Isola, "Modal coupling in one-dimensional electromechanical structured continua", Acta Mechanica 141, 37-50, 2000.

[9] D. W. Miller, and E. F. Crawley, "Theoretical and cxpcrimental investigation of spacc-realizable incrtial actuation for passive and active structural control", Journal of Guidance, Control and Dynamics 11(5), 449-458, 1988.

[10] F. dell'Isola, E.G. Honncke, M. Porfiri, "Synthesis of electrical networks interconnecting PZT actuators to damp mechanical vibrations", to appear in International Journal of Applied Electromagnetics and Mechanics.

[11] C. Niczreski, D. Brci, S. Balakrishnam, and A. Moskalik, "Piczoclectric Actuation: State of the Art", The Shock and Vibration Digest 33(4), 269-280, 2001. 